\title{
Modelos Mentais dos Estudantes do Ensino Médio e a Química dos alimentos
}

Mental model high school students and the chemistry of foods

João Rufino de Freitas Filho

Stefany Caroline S. Marques

Rinnely Cecília Lins de Melo

Jucleiton José Rufino de Freitas

\begin{abstract}
Resumo
Modelo Mental é definido como representação de uma idéia, objeto, evento, processo ou sistema. O conceito de modelo mental vem sendo usado em várias áreas do conhecimento. Baseado na Teoria dos Modelos Mentais de Johnson-Laird, estudantes de Ensino Médio foram observados durante dois semestres letivos com a finalidade de determinar o tipo de modelo mental que eles teriam utilizados durante a abordagem da temática química dos alimentos.

Palavras-chave: modelo mental, ensino de química, química dos alimentos

Abstract

Mental model is defined as representation of an idea, object, event, process or system. The concept of mental models is being used in several areas of knowledge. Based in the Mental Models Theory proposed by Johnson-Laird, high school were observed during two semesters with the objective of determining the type of mental models that they would have used during the boarding of the thematic chemistry of foods.
\end{abstract}

KeyWords: mental models, chemistry teaching, chemistry of foods. 


\section{Introdução}

A mente do ser humano tem a capacidade de guardar informações e a partir destas construir modelos internos de coisas externas. Para uma determinada informação não se pode formar apenas uma representação mental, ou seja, podem se ter vários construtos, onde estes se encontram inseridos nas representações Analógicas (Imagísticas) ou Proposicionais. Modelos mentais podem ser construídos a partir de percepção, imaginação, ou a compreensão de discurso. Eles estão sob imagens visuais, mas também podem ser resumo, representando situações que não podem ser visualizadas. Cada modelo mental representa uma possibilidade.

Rouse e Morris (1986) define modelos mentais como "os mecanismos em que os seres humanos são capazes de gerar descrições do sistema objeto e forma de funcionamento e as explicações do sistema observado sistema estados, e previsões do futuro sistema estados ".

Segundo Greca e Moreira (1997), os modelos mentais podem ser basicamente proposicionais, i.e., constituídos principalmente de proposições, ou basicamente imagísticos, ou seja, construídos predominantemente com imagens, ou, ainda, híbridos, quer dizer, formados por proposições e imagens.

Uma caracterização simples de um modelo mental é que ele é um modelo que existe na mente de alguém. Dessa forma, só podemos falar a respeito de nossa própria concepção do modelo mental de uma outra pessoa, o usuário do modelo. Intuitivamente a idéia é simples: pensar envolve a criação e a internalização de modelos simplificados da realidade. Entretanto, o conceito não pode ser considerado como unitário. Ao contrário, diferentes limitações e pressupostos são impostos no significado do termo pelas diversas comunidades que o empregam. $\mathrm{Na}$ Ciência Cognitiva, os modelos mentais são usados para caracterizar as formas pelas quais as pessoas compreendem os sistemas físicos com os quais interagem. Eles servem para explicar o comportamento do sistema, fazer previsões, localizar as falhas e atribuir causalidade aos eventos e fenômenos observados (Norman, 1983).

Assim, modelos mentais são representações práticas de partes da realidade. São como modelos em pequena escala, internos (na mente), os quais são usados para antecipar eventos, entender como as coisas funcionam, explicar o mundo etc. São basicamente representações mentais da realidade.

É importante entender que modelos mentais são aprendidos através da experiência do indivíduo, isto é, eles podem ser mudados, não são universais, nem inatos. São construídos principalmente pela experiência individual. Como os indivíduos estão inseridos em determinada cultura, os indivíduos desta cultura compartilham os mesmos ou semelhantes modelos mentais acerca de porções da realidade. 
Não existe um único modelo mental para um determinado estado de coisas. Ao contrário, podem existir vários, mesmo que apenas um deles represente de maneira ótima esse estado de coisas.

Sabendo que o Ensino Médio é composto por estudantes que nem sempre estão dentro da faixa etária adequada a seriação, no entanto, os mesmos têm facilidade de absorção de linguagens, ações e imagens através da interatividade entre professor, colegas e objeto de estudo. Segundo Vygotsky (1984) o processo de construção do conhecimento ocorre em uma complexa dinâmica interativa, da qual participam três elementos essenciais: o aluno, como sujeito do conhecimento; os conteúdos e os significados; o professor que atua como mediador. Sendo assim é necessário que haja uma relação entre professor e aluno para que essa interatividade aconteça, contribuindo para que o mesmo adquira conhecimento prévio permitindo-o produzir modelos mentais.

Quando perguntamos aos estudantes do Ensino Médio, qual a importância dos carboidratos, proteínas, lipídios e aminoácidos para a saúde do organismo humano? Acredita-se que através dos modelos mentais eles poderão construir ou representar a partir das informações recebidas. Isto é possível tendo em vista que Johnson-Laird, Gentner e Stevens (1983) afirmam que modelos mentais são: um construto psicológico que as pessoas formam na interação com outras pessoas, com o meio ou com algum artefato, de modo que lhes permita avaliar tal interação e predizer o comportamento dos sistemas em relações futuras.

Por outro lado, Gentner e Gentner (1983) identificaram dois modelos de eletricidade usados por um grupo de estudantes americanos: a analogia com um circuito hidráulico e a analogia com objetos em movimento:

Diante do exposto, neste trabalho procuramos analisar e discutir os diferentes tipos de modelos mentais dos estudantes do Ensino Médio sobre a temática Química dos alimentos.

\section{Metodologia}

A pesquisa foi realizada em situação real de sala de aula, com 25 alunos do Ensino Médio da zona rural do Município de Cupira/PE, no período de agosto de 2007 a maio de 2008.

A sistematização dos trabalhos realizados exigiu: a) encontros de estudo e planejamento coletivo das atividades; b) visita in lócus; c) coleta e organização de materiais para estudos e desenvolvimento das aulas; d) elaboração e aplicação de questionário; e) montagem de experimentos; f) pesquisa bibliográfica sobre a química dos alimentos (carboidratos, lipídios, aminoácidos e proteínas); g) relatórios das atividades desenvolvidas em sala de aula, h) apresentação das produções desenvolvidas pelos alunos à comunidade escolar, exposição oral. 
Foram envolvidos na proposta de trabalho pedagógico, o professor da disciplina Química, três alunos da graduação em Química e vinte e cinco estudantes do Ensino Médio.

A metodologia adotada para atingir os objetivos teve início com os estudantes fazendo investigação de cunho teórico para responder a questões do tipo o 1) Defina: a) carboidratos, b) lipídios, c) aminoácidos, d) proteínas; 2) O que são Esteróides? 3) O que é um amido? 4) O que é um monossacarídeo? 5) Qual é a diferença entre um aminoácido essencial e um não-essencial? Cite um exemplo de cada.

Este trabalho de pesquisa foi permanentemente norteado pela idéia da expressabilidade exterior das representações internas do estudante de modo refletido e fidedigno, ou seja, a idéia através da qual cremos que as manifestações representacionais externas do indivíduo (registros escritos e desenhos, expressão verbal por meio de perguntas, opiniões e asserções no caso de situação de sala de aula - interação direta) refletem de modo coerente as suas representações mentais internas. Assim, levamos em conta todas as manifestações individuais exteriores no intuito de as mesmas nos fornecerem traços correspondentes à operação mental do estudante em questão. Deste modo procuramos inferir se os estudantes modelizam (ou não) a Química dos alimentos, mas especificamente carboidratos, lipídios, aminoácidos e proteínas.

\section{Resultados e Discussão}

Partimos do pressuposto de que as pessoas raciocinam com modelos mentais, operam cognitivamente com modelos mentais, representam internamente o mundo com modelos mentais. Decorre daí que a pessoa que constrói um modelo mental de algum estado de coisas do mundo, algum fenômeno físico, por exemplo, chega a compreendê-lo, e à sua maneira, é capaz de explicá-lo e fazer previsões sobre ele. Reciprocamente, se a pessoa é capaz de explicar e fazer previsões sobre um certo fenômeno físico é porque tem um modelo mental dele, embora não necessariamente correto do ponto de vista da Química.

Estendendo este raciocínio para o caso de estudantes de Ensino Médio diríamos que se eles conseguem construir modelos mentais sobre os conteúdos que Ihes são ensinados, eles poderão compreender melhor os conceitos e leis físicas e explicar fenômenos físicos e químicos usando símbolos e equações que representam tais conceitos. Poderão também transferir a aplicação de tais modelos a outras situações. Quer dizer, eles poderão "testar" seus modelos perante novas situações, prevendo e explicando tais situações.

No trabalho realizado com estudantes da Zona Rural de Cupira/PE foram analisados vários pontos importantes no qual se referem aos modelos mentais dos estudantes envolvidos conforme as aulas expositivas, trabalhos em grupo, resolução de exercícios e as aulas contendo 
experimentos, principalmente os virtuais. De início os estudantes responderam perguntas sobre se existia ou não diferenças entre carboidratos e lipídios e, muitos levaram em consideração que havia diferença, porém não sabiam como expor, outros disseram que carboidratos era os constituintes de todos os alimentos.

As figuras 1 a 8 são representações usadas pelo Aluno ' $A$ ' para responder as perguntas:

1) Defina: a) carboidratos, b) lipídios, c) aminoácidos, d) proteínas;

2) O que são Esteróides?

3) O que é um amido?

4) O que é um monossacarídeo?

5) Qual é a diferença entre um aminoácido essencial e um não-essencial? Cite um exemplo de cada.
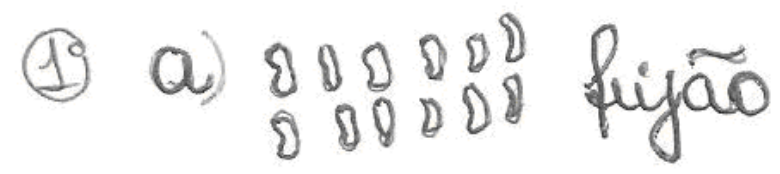

Figura 1: Representação mental para definir carboidratos

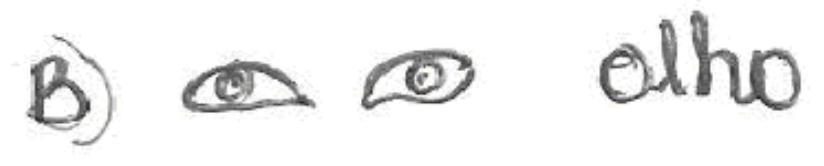

Figura 2: Representação mental para definir lipídio

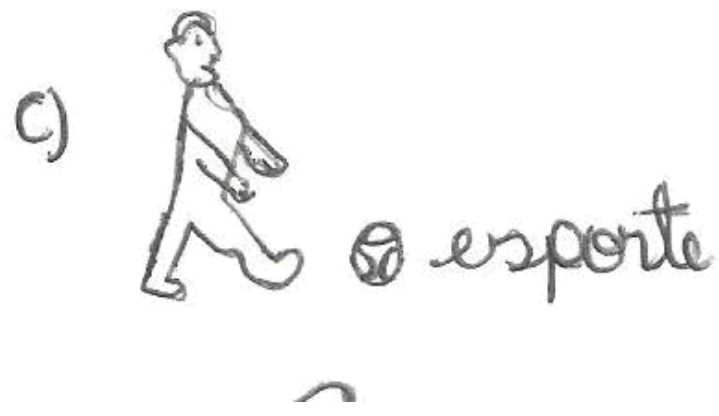

Figura 3: Representação mental para definir aminoácidos 


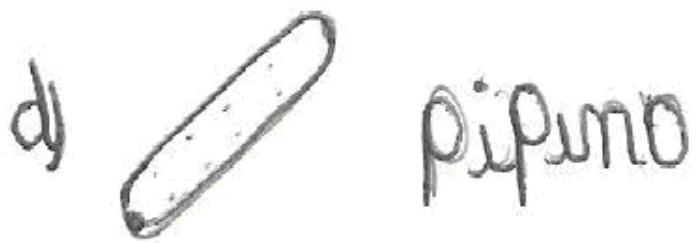

Figura 4: Representação mental para definir proteínas

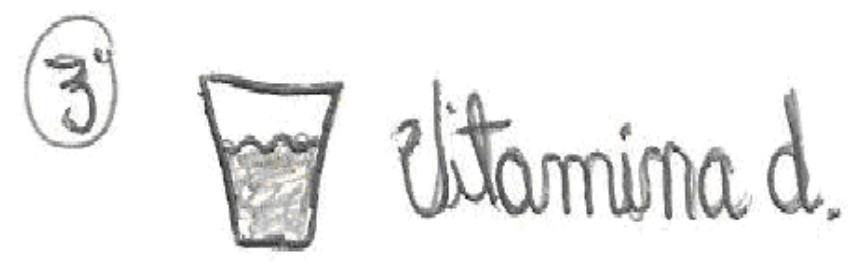

Figura 5: Representação mental para responder o que são esteróides.

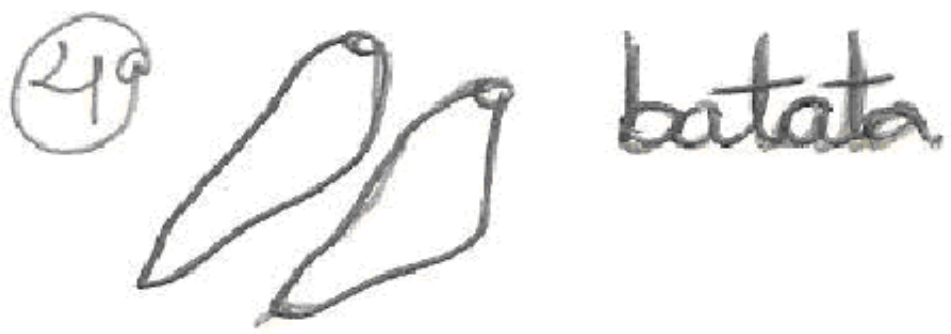

Figura 6: Representação mental para responder o que é amido.

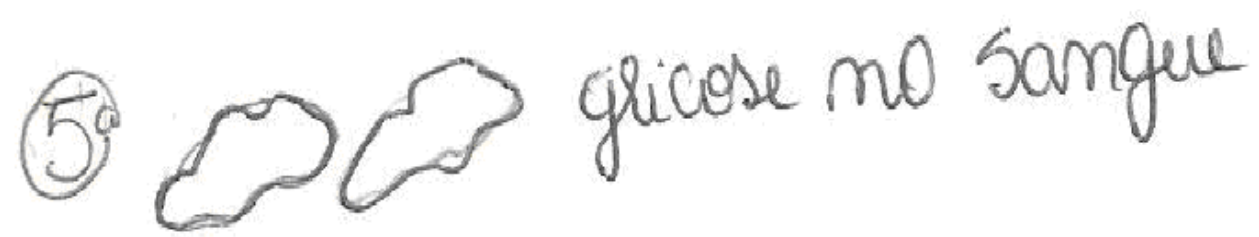

Figura 7: Representação mental para responder o que é monossacarídeo. 


\section{(65) Erent Remevi}

Figura 8: Representação mental para responder diferença entre aminoácido essencial e não-essencial.

O aluno ' $A$ ' procurou demonstrar o conteúdo exposto através de representações analógicas (imagísticas), suas representações foram totalmente analógicas.

Segundo Eisenck e Keane( 1994, p.184) as representações analógicas são não-discretas (não-individuais), concretas (representam entidades específicas do mundo exterior), organizadas por regras frouxas de combinação e específicas à modalidade através da qual a informação foi originalmente encontrada

Na figura 1, quando o aluno A procurou definir carboidratos utilizou algo comum a sua realidade, tendo em vista que o feijão é um tipo de carboidrato complexo que são ligados por longas fileiras de açúcares, são digeridos lentamente pelo organismo, fornecendo uma fonte estável de energia. Alem disso, também contém quantidades variáveis de fibras.

O aluno A, de acordo com a figura 2, definiu lipídios a partir de uma imagem do alimento alho. Percebe-se que o aluno acredita que o alho tem na sua constituição um maior percentual de lipídios (óleo), o que não é verdadeiro. O alho é constituído de carboidratos (maior quantidade), proteínas (quantidade intermediária) e lipídios (menor quantidade). Isto pode perceber nas respostas orais dadas pelas alunas.

Analisando a figura 3, percebe-se que o aluno representou um esportista procurando definir os aminoácidos, por um esquema de associação à energia necessária para se desenvolver esportes, o homem precisa de suplementos de aminoácidos, que tem como função ajudar no reparo, crescimento e desenvolvimento do tecido muscular.

O aluno A conforme figura 4, propôs um tipo de modelo de associação, onde pelo fato de existir proteínas estruturais que servem para dar firmeza e proteção aos organismos. O colágeno é um exemplo desse tipo de proteína, encontradas em cartilagens e tendões, supostamente ela associou ao uso diário de pepino na alimentação ou diretamente aplicado na pele. 
Conforme figura 5, o aluno A procurou definir os esteróides através da vitamina ' $d$ ', a qual é lipossolúvel, obtida a partir do colesterol, tem função muito importante na maioria das funções metabólicas e também musculares. A deficiência desse tipo de vitamina pode ocasionar a osteoporose. $\mathrm{O}$ interessante de sua representação mental é que ao tentar representar a vitamina ' $d$ ' através de algum alimento como, por exemplo, a manteiga, nata, gema de ovo e fígado, o aluno se utilizou da associação de um copo de vitamina.

Na figura 6, o aluno procurou representar o amido através de uma batata, pelo simples fato deste ser encontrado nos frutos e tubérculos vegetais, como aipim, batata, milho, entre outros; é importante na dieta como suprimento de energia, é o pó de carboidratos que mais se consome.

O aluno, de acordo com a análise da figura 7, propôs uma representação de definição interessante, pois, a glicose é um tipo de monossacarídeo que possui seis carbonos em sua estrutura, e é o único hidrato de carbono que circula no sangue, o aluno conseguiu captar a informação de maneira correta, associando a definição a um elemento vital do seu corpo.

Finalmente na figura 8, o aluno não apresentou o modelo mental referente à pergunta que lhes foi proposta. Há 20 tipos de aminoácidos que participam da síntese das proteínas, os quais: 08 são essenciais e 12 não-essenciais. Os aminoácidos essenciais se diferem dos nãoessenciais pelo fato de não serem sintetizados pelo nosso organismo, onde são requeridos para o crescimento e manutenção dos tecidos. O aluno se valeu de uma propaganda televisiva do produto de beleza Renew, para representar um aminoácido essencial.

Dando continuidade a análise as figuras 9-16 a seguir são representações usadas pelo Aluno 'B' para responder as perguntas acima propostas.

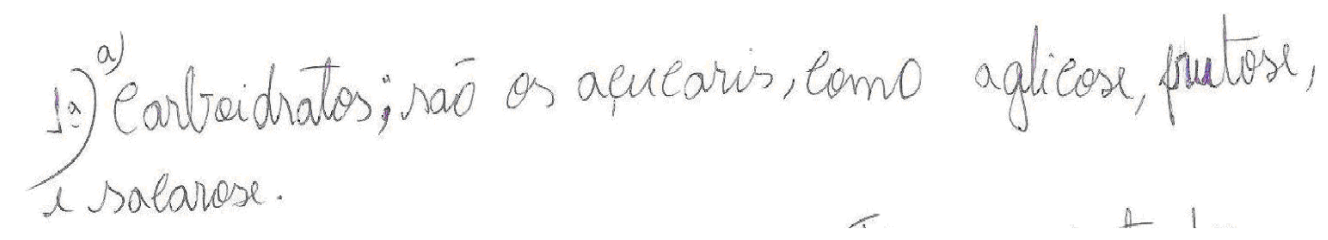

Figura 9. Representação mental para definir carboidratos.

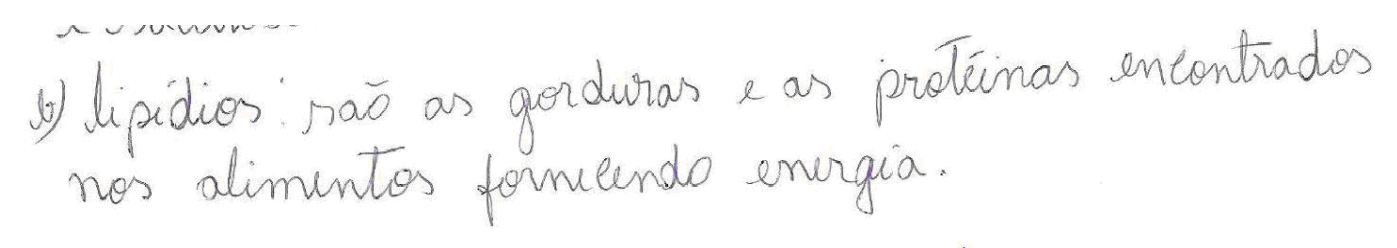

Figura 10. Representação mental para definir lipídios 


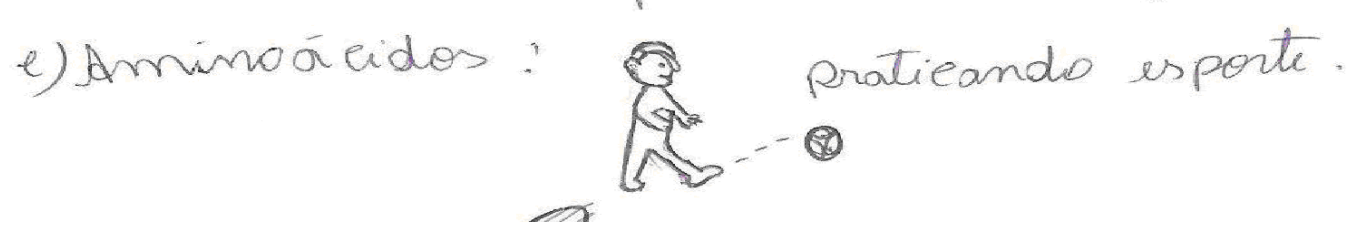

Figura 11. Representação mental para definir aminoácidos

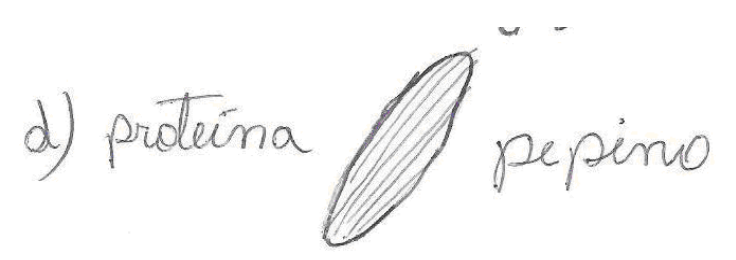

Figura 12. Representação mental para definir proteínas.

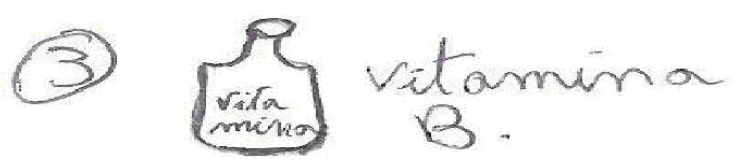

Figura 13. Representação mental para definir esteróides.

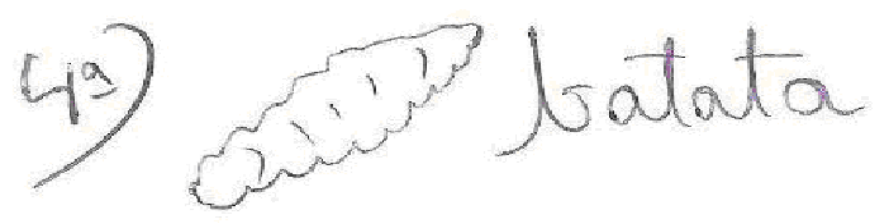

Figura 14. Representação mental para definir amido.

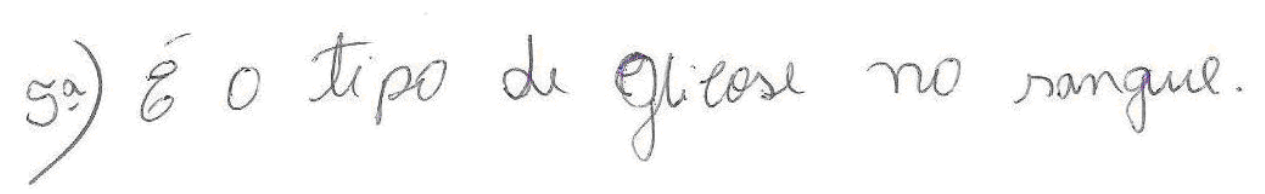

Figura 15: Representação mental para definir monossacarídeo. 


\section{6a) Proteinas e leueina.}

Figura 16. Representação mental para diferenciar $A A$.

O aluno ' $\mathrm{B}$ ' produziu modelos mentais de uma forma parcial, ou seja, parcialmente analógica e parcialmente proposicional.

A analogia pode ser total ou parcial, isto é, um modelo mental é uma representação que pode ser totalmente analógica ou parcialmente analógica e parcialmente proposicional (Eisenck e Keane, 1994, p. 209).

$\mathrm{Na}$ figura 9, o aluno apresentou um modelo mental proposicional, expressando verbalmente de forma adequada a definição de carboidratos.

O aluno, conforme a figura 10 desenvolveu a mesma seqüência lógica da figura anterior (figura 9).

Conforme figura 11, o aluno definiu aminoácido através de uma representação analógica, ou seja, através de imagens, demonstrando de forma adequada o conceito de aminoácidos.

De acordo com a figura 12, o aluno segue a mesma seqüência lógica da figura anterior (figura 11).

Analisando a figura 13, percebe que aluno equivocadamente tentou demonstrar um esteróide através de uma vitamina ' $B$ '. $O$ esteróide pode ser representado através da vitamina ' $D$ '.

Na figura 14, o aluno segue representando através de imagens, onde utiliza o desenho de uma batata para definir amido.

De acordo com a figura 15, o aluno define um monossacarídeo de forma correta através de uma representação proposicional, ou seja, associa glicose a sangue.

Finalmente na figura 16, o aluno tenta diferenciar os aminoácidos através de um modelo mental proposicional, no entanto, se equívoca quando define proteína como uma leucina, pois sabe-se que uma proteína pode conter leucina (aminoácido) na sua estrutura, e nunca ser definida como leucina.

As figuras 17-24 a seguir são representações usadas pelo Aluno ' $\mathbf{C}$ ' para responder as perguntas acima propostas. 
(1)

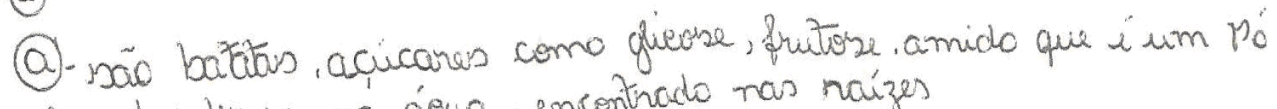
que dussolve-ne na água encontivado nas naízes

Figura 17. Representação mental para definir carboidratos

1. (b) distribuido res organismos vivos, phesente ra vitamina 20.

Figura 18. Representação mental para definir lipídios

1. C) Sä blass moteculanos que repoem inengia caracterizados como sintizados econtramos na sefa, feifao, cornes.

Figura 19. Representação mental para definir Aminoácidos

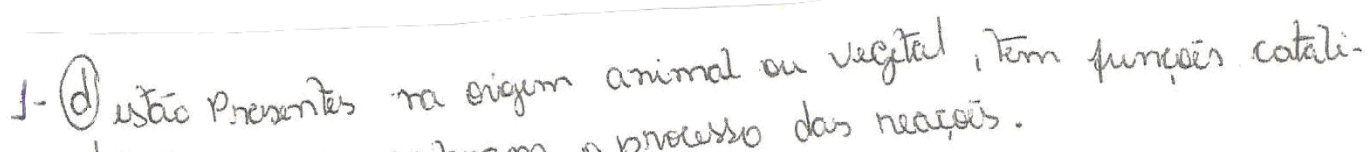
zadoras on rega acieram oprocesso das neacous.

Figura 20. Representação mental para definir proteínas.

(3) Sáo anabolizantes us tipo de edestenol qui ayudam no proasso de cumento de masia mistilar.

Figura 21. Representação mental para definir esteróides. 
(4) Um dos constiturntes dos carboidratos íum po encontrado nos turbecuhos segjais on sejer raizes.

Figura 22. Representação mental para definir o que é amido

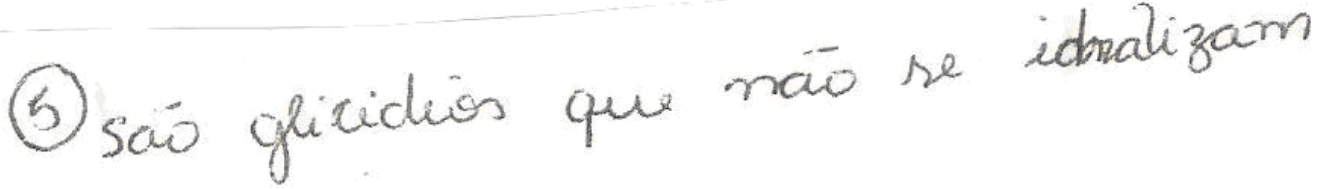

Figura 23. Representação mental para definir o que é monossacarídeo.

6) essencial naio pode ser suntetizados 2x: glutamina now essencial bo pode us sunktizados ex: Lecena

Figura 24, Representação mental para diferenciar AA.

O aluno ' $C$ ' apreendeu as informações externas, e de uma forma total produziu apenas representações proposicionais de acordo com expostos nas figuras 17-24.

Segundo Johnson-Laird, representações proposicionais são cadeias de símbolos que correspondem à linguagem natural, modelos mentais são análogos estruturais do mundo e imagens são modelos vistos de um determinado ponto de vista (1983, p.165).

Tendo em vista a seqüência lógica que o aluno $C$ apresentou, e após avaliação minuciosa das respostas dadas, conclui-se que, o mesmo apreendeu e produziu de uma forma que the é peculiar, ou seja, a preferência por expressar através de construtos verbais, a qual se denomina representação proposicional. 
Convém salientar que um modelo não supera o outro, mas todos são formas de representações internas do ambiente externo e que apenas cada estudante procurou expressar da melhor forma como o mesmo havia compreendido e ainda buscando associar as informações novas com algo já existente em sua mente. É relevante também observar, de modo geral, que alguns estudantes têm mais facilidades que outros para realizar tais tipos de associação.

Os estudantes do 30 ano do ensino médio, objeto de estudo, apresentaram maior tendência a representar os modelos mentais através da escrita estando ligado à representação proposicional, devido ao fato, de que a exposição da temática abordada ter sido mais verbal, com menor representações imagísticas, sendo assim, é notável que o estudante é produto do meio, ou seja, a influência do contexto no qual esta inserido reflete nas suas representações internas.

\section{Conclusões}

Ao analisar os tipos de modelos mentais usados por estudantes do ensino médio sobre a temática: Química dos alimentos, mas especificamente, carboidratos, lipídios, aminoácidos e proteínas; ficou constatado que a construção dos modelos mentais depende do contato do aluno com o exterior. É notável que a forma como o conteúdo é abordado interfere na criação de suas representações, ou seja, os recursos utilizados pelo professor contribuem direta ou indiretamente para ampliação do conhecimento do mesmo. $O$ aluno apresenta facilidade em representar através de símbolos verbais à medida que ele costuma participar de aulas versadas em exposição oral, a qual estimula o tipo de Representação Mental Proposicional.

Conforme o tipo de representação mental que os alunos utilizavam durante as aulas quer convencional, quer demonstrativas - como também nos testes avaliativos pode-se concluir que alguns, embora trabalhassem nos testes avaliativos utilizando proposições desvinculadas de modelos, como aluno $D$, nas aulas e na interação com o professor, parecia ter utilizado um modelo mental sobre o conceito de alimentos que incluía a carboidratos e lipídios como agente responsável pela questão do açúcar e gorduras no sangue. Outros alunos trabalharam durante as aulas com modelos basicamente proposicionais, ou seja, interligando diferentes conceitos como, amido, hidrólise, glicose, açúcar invertido etc.

De acordo com a análise da representação mental dos estudantes constatou-se que o maior percentual dos modelos utilizados pelos estudantes foi proposicional. $O$ aluno $A$ ao responder as questões propostas usou modelo imagísticos e algumas respostas foram equivocadas. 
Por outro lado, acredita-se que os estudantes que não construírem modelos mentais poderão até lembrar e usar símbolos e fórmulas químicas que representam os conceitos, mas não conseguirão explicar, prever e transferir seu conhecimento. Quer dizer, não darão evidências de uma aprendizagem significativa. (Moreira, 1997).

\section{Referências}

Eisenck, M.W. e Keane, M.T. (1994). Psicologia cognitiva: um manual introdutório. Porto Alegre, RS: Artes Médicas. 490 p.

Gentner, D. and Gentner, D. R. (1983). Flowing waters or moving crowd: Mental models of electricity. In D. Gentner and A. L. Stevens (Eds.), Mental Models. Hillsdale, NJ: Lawrence Erlbaum (pp. 99-130).

Gentner, D. and Stevens, A.L. (1983). Mental Models. Hillsdale, NJ: Lawrence Erlbaum.JohnsonLaird, P. (1983). Mental Models. Cambridge, MA: Harvard University Press.

Moreira, M. A.( 1997). Aprendizagem significativa: um conceito subjacente. In: Encuentro Internacional Sobre el Aprendizaje Significativo, , Burgos. MOREIRA, M.A. et al. (Orgs.) Actas. Burgos: Universidade de Burgos, 1997. p. 19-44.

Norman, D.A. (1983). Some observations on menatl models. In D. Gentner \& A.L.Stevens (Eds.) Mental Models. Hillsdale, NJ: Lawrence Erlbaum (Pp. 07-15).

Rouse , W.B, \& Morris, N.M (1985). On looking into the black box: Prospects and limits in the search for mental models (Report No.ONR-TR-85-2). Arlington, VA: Office of Naval Research, Personnel and Training Research Programs Office. (ERIC Document Reproduction Service No. ED 268 131). 
João Rufino de Freitas Filho: Pós-doutor em Química pela Université Claude Bernard (França). Docente da Universidade Federal Rural de Pernambuco - UFRPE / Unidade Acadêmica de Garanhuns - UAG. joaoveronice@yahoo.com.br.

Stefany Caroline S. Marques : graduada em Licenciatura em Química pela Faculdade de Formação de Professores da Mata Sul - FAMASUL, Palmares/PE. Professora do Ensino Médio da Escola Estadual Maria de Lourdes Temporal, Cupira/PE. stefany_som@hotmail.com.

Rinnely Cecília Lins de Melo : graduada em Licenciatura em Química pela Faculdade de Formação de Professores da Mata Sul - FAMASUL, Palmares/PE. Professora do Ensino Médio da Escola Estadual Prof. Carlos José Dias da Silva, São José da Coroa Grande/PE._rinnelylins@hotmail.com.

Jucleiton José R de Freitas : licenciando em química pela Universidade Federal Rural de Pernambuco, UFRPE. jucacleiton@yahoo.com.br. 